\title{
Blended Teaching Practice in Digital Signal Processing Course
}

\author{
Xia Wang* \\ School of Electronic and Information Engineering \\ Hebei University of Technology \\ Tianjin, China \\ wangyuehui3@163.com \\ Cuixiang Liu \\ School of Electronic and Information Engineering \\ Hebei University of Technology \\ Tianjin, China \\ liucuix@126.com
}

\author{
Baozhu Wang \\ School of Electronic and Information Engineering \\ Hebei University of Technology \\ Tianjin, China \\ wbz_china@126.com \\ Cheng Zeng \\ School of Electronic and Information Engineering \\ Hebei University of Technology \\ Tianjin, China \\ zeng_ch@126.com
}

\begin{abstract}
Aiming at the training objectives of engineering education certification, based on OBE pedagogical idea, this paper researched blended teaching method and carried out teaching process design and practice. Following the rules of student-centered and teacher-led, blended teaching scheme was designed. For the teaching contents, we separated them into five modules, and each module included several knowledge points for online learning and discussion. Teachers established course website in Cloud Class of Hebei University of Technology, and uploaded multimedia courseware, teaching videos, etc. Using these online resources, through MOOC, flipped classroom, and fragmentation learning, integration of online learning and offline learning was realized. Blended teaching emphasized assessments of learning process and abilities of the students, so regular grade combined online evaluation with traditional evaluation. Through autonomous learning, discussion in groups, interaction with others, counseling and answering links, this teaching and learning method develops students' abilities to analyze and solve practical engineering problems.
\end{abstract}

Keywords-blended teaching; flipped classroom; teaching design; online learning; Digital Signal Processing course

\section{INTRODUCTION}

In order to adapt the demand of "double first-class" construction, it needs to carry out reformations on teaching methods and teaching means. Blended teaching is a teaching mode by using different means and technologies under the background of higher education informatization. It combines online teaching with traditional face-to-face teaching to form a new mode of "online plus offline". The method is an effect mode to improve autonomous learning ability and engineering application ability of students.

Many universities at home and abroad have been carrying out reform researches and explorations in this respect. Zheng investigated and analyzed the status quo of blended teaching in domestic colleges[1]. Fu et al. designed a "five-stage" blended

Education and Teaching Reform Research Project of Hebei University of Technology(201803019), Higher Education and Teaching Reform Research and Practice Project of Hebei Province(2017GJJG024, 2018GJJG045). teaching model based on Small Private Online Course (SPOC)[2]. Shanghai Jiao Tong University developed engineering education practice based on Massive Open Online Course (MOOC) and blended teaching in Principle and Technology of Database course[3]. Tang et al. constructed blended learning mode with "online teaching, classroom teaching and practice teaching" based on "Internet Plus"[4]. Wang et al. proposed a blended teaching method suitable for large-scale classroom to solve the problems of difficult classroom management and insufficient enthusiasm of students in the Circuit Principle course[5]. Afsharian et al. reviewed the current progress of blended teaching in higher education and limitations under the background of engineering education[6]. Tikadar et al. proposed a blended learning platform which ICT and traditional classrooms were blended to improve teachinglearning process[7]. Lo et al. combined traditional learning mode with multimedia videos and web-based mode, such as online quizzes, interactive discussion[8].

As a basic course of discipline and specialty, Digital Signal Processing plays a connecting and important role in the whole curriculum system, so it is necessary to reform teaching methods in order to improve student's studying effects. In the basis of OBE pedagogical idea, combined with "Engineering Education Certification”, Communication Engineering major and Information Engineering major of Hebei University of Technology carry out blended teaching practice.

\section{Blended TEACHING OBJECTIVES}

According to "Engineering Education Certification" professional training objectives, the teaching objectives are divided into three aspects.

\section{A. Knowledge Objective}

Through learning this course, students should master and utilize frequency domain analysis method of discrete time signal and system, design and implementation of digital filter, and so on. 


\section{B. Ability objective}

Through learning this course, a multi-level ability hierarchy can be built: the ability of researching, analyzing and solving practical engineering problems by using theoretical knowledge synthetically, the ability of simulating by using software.

\section{Quality objective}

Through learning this course, consciousness of students' teamwork, communication with others, autonomous learning and lifelong learning can be cultivated.

\section{Blended TEACHING SCHEME DESIGN}

Teaching scheme is designed based on teaching objectives as described earlier and the rules of student-centered and teacher-led, its hierarchy framework is shown in Fig.1.

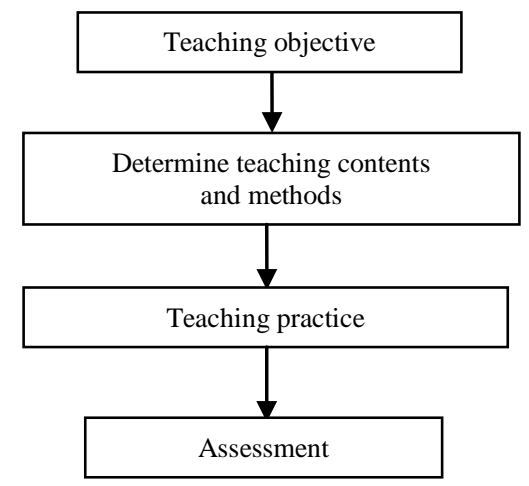

Fig. 1. Teaching scheme framework

\section{A. Teaching content}

Teaching contents determination is important because the features of the course: theoretical abstraction, strong practicality, connected with mathematics and computer closely. The theoretical teaching and experiment contents, which relate to the courses before and after, are adjusted to solve the problem of class hour limits. After analyzing contents of Signal and Linear System course and this course, it is found that parts of the contents are overlapped, and the key points are different to some extent, so the contents of two courses are distributed respectively again. Furthermore, interdisciplinary knowledge is introduced in teaching to construct complete knowledge system.

In the process of system formation of this course, the teaching and experiment contents are divided into five knowledge modules for systematizing. In order to understand and discuss easily for students in blended learning, knowledge points are analyzed, then each module is separated into several points. These knowledge points and corresponding videos are uploaded into Cloud Class of Hebei University of Technology, and provided to students for autonomous learning.

\section{B. Teaching method}

Teaching method design is based on engineering education and professional training targets. Through using advanced educational means, such as MOOC, flipped classroom, fragmentation learning, integration of online-offline theory and practice teaching are realized, and student's abilities in solving problems and studying independently are cultivated. In the process of teaching, interests and initiatives in learning of students are enhanced by using cloud class.

Before class, teacher provides knowledge points which have been prepared in website to students; students preview these contents by watching online videos, and prepare discussing materials. In class, the contents of knowledge are expounded and discussed by students individually or in groups, thus students' preview degree of knowledge is acquainted by teacher. For key points, teachers guide the students to learn. For problems and practical cases which are difficult to understand, programming simulations are used to show the results directly. At last, in the basis of fragmented learning, all points of this lecture are summarized by teacher to form the organic combination of fragmentation and systemization.

\section{Teaching process}

The organization form of blended teaching is in groups, aiming to develop cooperation ability and enhance team awareness. Teaching activities not only involve in the class, but also extend to the pre-class and after-class.

Before class, contents to learn, relative problems, reference books and videos are provided to the students, then students learn by themselves and carry on research-based learning activities in group.

In class, the roles of teacher and students are flipped, there are several modes adopted, student lecturing and teacher assessing, student lecturing and student assessing, teacher lecturing, discussing between students and teacher, and so on. In this process, teacher pays attention to students' reactions, encourages students interact with teacher and other students.

After class, except for exercises in the textbook, there are some extra homework which mainly involves application of multi-knowledge points, students propose and realize the scheme of the problems, this step is aim to train the ability of solving engineering problems. Meanwhile, we pay attention to the after-class counseling and answering step, not only using face-to-face mode in fixed or unfixed time, but also through the network, such as QQ. QQ group is established for each grade, if students have some problems, even extracurricular knowledge, such as voice, image signal processing, they can discuss in QQ group with teacher and other students.

\section{Assessment}

The assessment of the course is an important step of teaching process, which plays supervisory and guiding role in students' learning. Total grade is consisted of final exam grade and regular grade. It comprehensively evaluates learning situation from pre-class to after-class.

Blended teaching emphasizes the assessment of learning process and ability of students, so proportion of regular grade increases. Regular assessment is divided into two parts; online assessment includes cloud class tests of each knowledge module, online video watching situation of every student. Offline assessment includes material preparation and knowledge point summary, classroom discussing participation, 
class quizzes, experiments and homework, and so on. The percentage is shown in Fig.2.

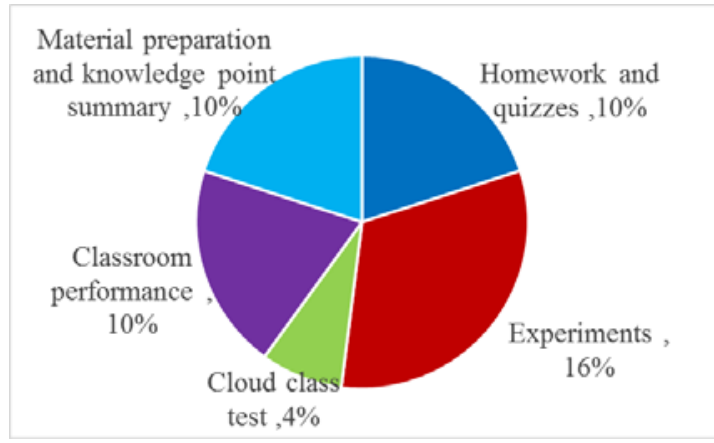

Fig. 2. Regular grade

\section{PRactice AND EFFECT OF Blended Teaching}

In blended teaching practice of Digital Signal Processing course, students watched videos of knowledge points before class, discussed and found out answers for the problems which teacher raised in advance. In the classroom, the discussion focused on key points, difficult points and software realization of fragmentation points, homework analysis and so on. 20 percent of the total class hours belonged to the teacher to introduce studying method, key and difficult points of each module, lecture and summarize, 80 percent of the total class hours carried on blended learning. The school has built smart classrooms, in each smart classroom an electronic board and several display screens was provided. The electronic board can be used for displaying multimedia courseware or writing and marking, screens can display students' simulating results or materials. The smart classroom constructed an interactive teaching environment, which provided a guarantee for blended teaching, it was very convenient for students. Each studying group carried a laptop to the classroom and can use it for program simulating, and simulation results of the students on the laptop can be displayed on the corresponding display screen. Fig.3 shows the scene of blended teaching in the smart classroom.

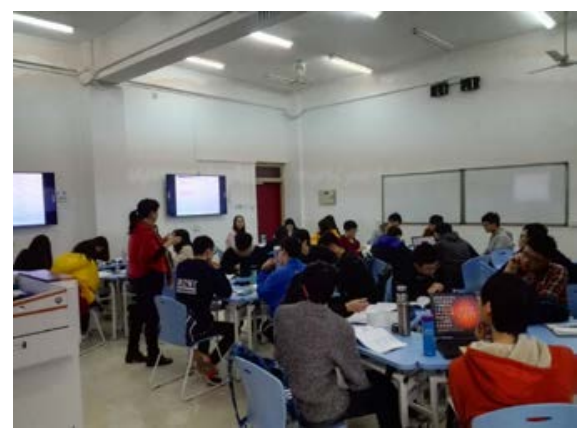

Fig. 3. Blended teaching in the smart classroom

Through the practice of blended teaching, the students' application and practical abilities of signal analysis, system design were improved. Teaching achieved a better effect, and obtained students' recognition.

At the end of the semester, the questionnaire survey was conducted among students. The questionnaire included single- choice questions and short answer questions, contents related to online learning time over the network, preparation time for knowledge points of each module, recognition and adaptability of the teaching mode, effectiveness, suggestions, etc. For example, survey result of online learning time of the students is shown in Fig.4, preparation time before class is shown in Fig.5.

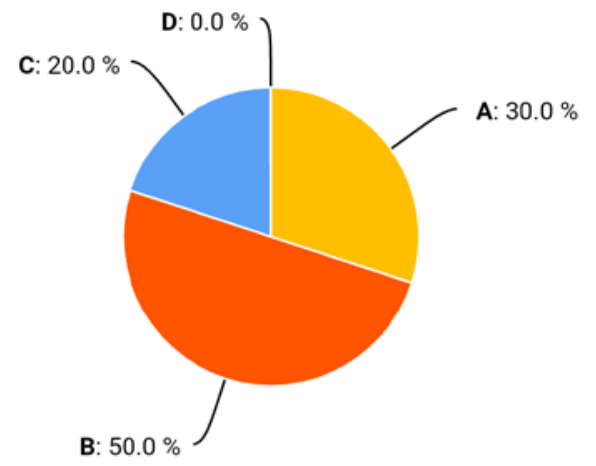

Fig. 4. Online learning time

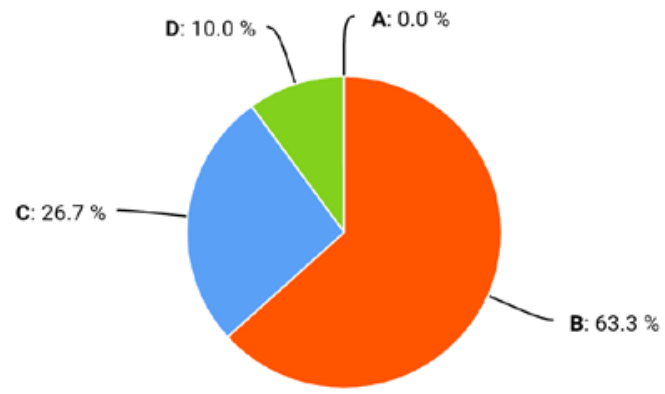

Fig. 5. Preparation time before class

For two questions above, each had four choices A, B, C and $\mathrm{D}$, and the four choices denoted less than 1 hour, 1-2 hours, 3-4 hours, more than 5 hours respectively. From the figure, it can be seen that most of the students cost a lot of time to prepare for class learning and discussion.

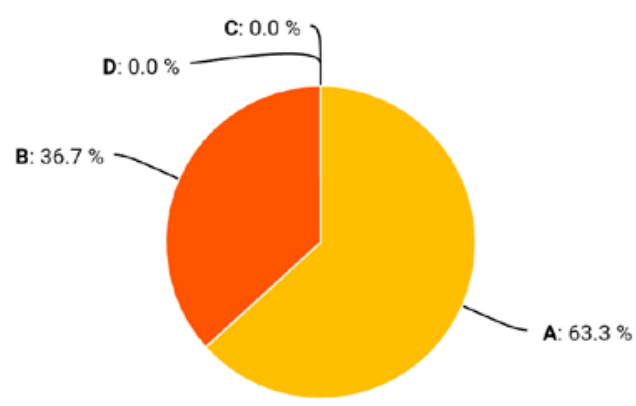

Fig. 6. Recognition and adaptability of the teaching mode

In the questionnaire, teaching mode recognition and adaptability statistics of the students were also made. And the results are shown in Fig.6.

The results show that most students recognize and adapt for this mode. 
In short answer question section, students gave their opinions to blended teaching, some of the answers list below.

- $\quad$ Student 1: The method fully mobilized the initiative of learning, make me put attention into learning in class and after class.

- Student 2: I thought blended learning method was good, because it broke up the traditional teaching mode, and let students study happily.

- $\quad$ Student 3: Innovative, worth popularizing.

- $\quad$ Student 4: The students’ initiative was promoted.

- $\quad$ Student 5: Blended teaching let us preview contents carefully before class, we can understand the key points of the course, and if I had some problems, I can discuss with teacher and classmates in class.

- $\quad$ Student 6: The more involved, the more interesting.

- $\quad$ Student 7: Blended teaching need students to preview before class, discuss in class, and review after class, it deepened my comprehension and mastery of the course and achieved better results.

And there are also some suggestions and advice from students for future teaching.

- $\quad$ Student 8: I hope to provide more opportunities for students to participate.

- Student 9: Grouping can be more optimization.

- Student 10: Sometimes it cost too much time to prepare for blended teaching.

\section{SUMMARY}

Aiming at improving initiative of students, developing ability of autonomous learning, this paper carried on the exploration and the practice of blended teaching. From setting teaching objectives to designing teaching contents, methods, means, processes and assessments, the practice has achieved good effects. But there are still some questions need to be solved, such as, it cost much time before class, optimization of grouping, and the degree of students' participation in class, these will be explored in future researches.

\section{ACKNOWLEDGMENT}

Thanks for Cloud Class of Hebei University of Technology providing platform to establish course website. It's convenient for students to learn online, and it provides strong support for the blended teaching of the course.

\section{REFERENCES}

[1] Jing Zheng, "On status quo of blended teaching and learning in domestic higher education," Heilongjiang Researches on Higher Education, pp.44-48, December 2018. (In Chinese)

[2] Yanfang Fu and Hao Yang, "Design and practice of blended teaching model based on SPOC," Vocational and technical education, vol.38, pp.36-41, September 2017. (In Chinese)

[3] Zhen Huang, "Exploration and practice of engineering education based on MOOC and blended teaching," Research in Higher Education of Engineering, pp.11-13, August 2016. (In Chinese)

[4] Bo Tang, Jianyi Kong, Liangcai Zeng, Guozhang Jiang and Yu Hou, "The blended learning mode based on 'Internet plus'," Higher Education Development and Evaluation, vol.34, pp.90-99, May 2018. (In Chinese)

[5] Kun Wang, Liqin Zhou, Liqiang Zhang and Shengbo Qi, "Research on blended teaching method suitable for big class-Taking "Circuit Principle' course as an example," Modern Educational Technology, vol.29, pp. 33-38, May 2019. (In Chinese)

[6] Azadeh Afsharian, Subarna Sivapalan and Shahrina binti Md Nordin, "Blended learning \& the higher education classroom: a critical review of developments within engineering education," 7th World Engineering Education Forum, pp.182-187, November 2017.

[7] Subrata Tikadar, Samit Bhattacharya and Venkatesh Tamarapalli, "A blended learning platform to improve teaching-learning experience," 18th International Conference on Advanced Learning Technologies, pp.87-89, July 2018.

[8] Chui-Man Lo and Kwan-Yee Tang, "Blended learning with multimedia e-learning in organic chemistry course," 2018 International Symposium on Educational Technology, pp.23-25, July 2018. 